\title{
Introduction to the Colloquium
}

Cary Mitchell

Purdue University, West Lafayette, IN
$\mathrm{P}$ roduction in many sectors of food and ornamental horticulture is rapidly shifting overseas, where growth climates are favorable and labor and production costs are cheaper than in the U.S. The paradox is that costs of fossil-fuel-based energy for transporting horticultural commodities long distances also are rising, and prospects for imported oil products are uncertain and subject to political leverage as well as to increasing global supply and demand dynamics. Food security is another source of concern regarding eventual net dependence upon offshore production of fresh produce. Devastation of certain sectors of U.S. horticulture is having a negative impact on regional economies as global market value of the total horticulture industry climbs toward the hundreds of billions of dollars worldwide and the U.S. loses competitive market share.

Energy costs for production of horticultural crops are a significant component of total cost, especially in areas where greenhouse heating and supplemental lighting requirements in the winter, and unachievable cooling requirements in the summer, create an unprofitable situation. Year-round, local production of horticulture crops using electric lamps would be feasible if sufficient energy were available at reasonable cost. The long-term solution to the dilemma of rising food prices and lost market share lies, in part, in combining existing and emerging tech- nologies to harness renewable energy sources locally and use them to create an economically viable controlled-environment agriculture (CEA) industry. Canadian and northern European producers have demonstrated that this approach is feasible, and with a few key technical innovations, a U.S.-based CEA could make the United States less dependent upon horticultural imports, could jump-start high-tech, local production enterprises, and decrease U.S. dependency on foreign oil products. Although several bioderived fuels are receiving a great deal of attention, the one that might benefit horticultural crop production most directly is methane. Rather than produce liquid biofuels that require storage and transportation to sites of use (e.g., ethanol, biodiesel), protected horticulture (greenhouses, warehouses, row tunnels) could immediately use methane gas produced nearby or on site as a source of fuel for combustion, for microturbines, or for fuel-cell reactions. Horticultural production enterprises clustered near landfills, feedlots, food-process plants, and municipal waste-treatment facilities could readily leverage the availability of bioenergy substrates.

The four presentations that follow address the integration of bio-based energy acquisition with agricultural production. Janes et al. describe a greenhouse aquaponics system powered by landfill gas. Chynoweth outlines the process of generating methane gas from renewable organic waste feedstocks by means of anaerobic digestion. Scott et al. develop the potential for use of dairy-farm waste as a source of energy for fuel cells and how this application could be linked to protected horticulture. Kephart and Rutzke describe the federal Sun-Grant Initiative, which reflects potentialR \& D empowerment for transitioning US agriculture from a fossil-fuel to a biofuelbased economy. Each presentation deals with integration of protected crop-production systems with technologies that offer renewable, bioderived energy. Considerable research and development is needed to optimize conditions for the efficient conversion of waste biomass to substrates that that can be converted to high-grade fuel, but even harnessing unoptimized bioconversion of organic waste to usable energy where natural substrates abound could jump-start sectors of CEA now in urban areas where market demand is substantial and constant. Application and improvement of the bridging technologies described in this proceedings hold the key to empowering local CEA production of high-intrinsic-value crops and making CEA industries profitable worldwide. Investment entrepreneurs should be very interested in the global prospects of this bridging, high-tech CEA! 